\title{
The incidence of Metabolic Syndrome in Subclinical Hypothyroid patients
}

\author{
Harun Düğeroğlu ${ }^{1}$ \\ ${ }^{1}$ Department of Internal Medicine, Faculty of Medicine, Ordu University, Ordu, Turkey \\ Received: 06 May 2019, Accepted 10 June 2019, Published online: 28 August 2019 \\ (C) Ordu University Institute of Health Sciences, Turkey, 2019
}

\begin{abstract}
Objevtive: The aim of this study was to evaluate the incidence of metabolic syndrome, a risk factor for chronic diseases such as cardiovascular diseases, diabetes mellitus and stroke, in patients with subclinical hypothyroidism.

Methods: A total of 108 patients with subclinical hypothyroidism followed in the outpatient clinic of Ordu University Faculty of Medicine Training and Research Hospital between 2015-2018 were included in the study. Height, waist circumference, weight, blood pressure, High Density lipoprotein (HDL) cholesterol and triglyceride levels and fasting blood glucose levels were recorded from the archive records of the patients. Body Mass Index (BMI) was calculated. Metabolic Syndrome (MetS) diagnoses were made according to the National Cholesterol Education Program Adult Treatment Panel III (NCEP ATP III) guidelines.

Results: Of the 108 patients included in the study, 74 (68.5\%) were female and 34 (31.5\%) were male. The mean age of the female patients was $38.3 \pm 12.5$ years and the mean age of the male patients was $40.5 \pm 11.7$ years. In this study, the prevalence of MetS was $42.6 \%$ (47.3\% in females and 30.8\% in males) in patients with subclinical hypothyroidism. MetS incidence was 1.5 times higher in female patients than in male patients. Among all patients, the most common MetS component was low HDL cholesterol (54.6\%) and abdominal obesity (52.8\%).

Conclusion: The incidence of MetS was higher in female patients with subclinical hypothyroidism than in male patients. In addition, close follow-up of patients with subclinical hypothyroidism in terms of Metabolic Syndrome, which is a risk factor for many chronic diseases such as diabetes mellitus, cardiovascular diseases and stroke, will benefit in reducing the mortality of patients.
\end{abstract}

Key words: Subclinical hypothyroid, metabolic syndrome, incidence.

Suggested Citation: Dugeroglu H. The Incidence of Metabolic Syndrome in Subclinical Hypothyroid Patients. Middle Black Sea Journal of Health Science, 2019; 5(2): 47-53.

Address for correspondence/reprints:

\section{Harun Düğeroğlu}

Telephone number: +90 (530) 4641575

E-mail: harun.dugeroglu@ @otmail.com

DOI: $10.19127 / \mathrm{mbsjohs.561137}$

\section{Introduction}

Metabolic Syndrome (MetS), as in the whole world, is a definition that includes important risk factors for diseases with high mortality rates such as diabetes mellitus, cardiovascular disease and stroke in our country (Balkau et al., 2007). Today, the diagnosis of MetS is based on the National Cholesterol Education Program Adult Treatment Panel III (NCEP ATP III) guidelines, which is accepted by many researchers (National Cholesterol Education Program (NCEP) Expert Panel on Detection, 2002). According to NCEP ATP III criteria, low HDL cholesterol level, high 
triglyceride level, increased plasma glucose level, increased waist circumference and increased blood pressure are diagnosed by the presence of three and / or more of the five criteria (National Cholesterol Education Program (NCEP) Expert Panel on Detection, 2002).

In many literature studies, the prevalence of MetS is seen between 7-46.5\% in women and 8$24.2 \%$ in men in the adult population (Ford et al., 2002; Gupta et al., 2003). However, many parameters such as age, gender, dietary habits, physical activity level, diet and genetic structure affect the prevalence of MetS. MetS is also a proinflammatory and prothrombotic state (Reaven, 1988). In one study, it is thought that the most important reason for MetS development is decreased insulin sensitivity and increased insulin level (Grundy, 2006). In another study, it has been observed that patients with MetS have increased mortality by reasons such as diabetes, cardiovascular diseases and stroke (Balkau et al., 2007).

Nowadays, especially in the excess or lack of thyroid hormones, there are significant changes in the waist circumference, weight and Body Mass Index (BMI) of individuals (Lonn et al., 1998). In addition, this poses a risk for many important diseases such as cardiovascular diseases, diabetes and stroke (Kllein, 1989). Increased vascular resistance in hypothyroid patients may cause blood pressure development (Morkin et al., 1983). Although the effect of TSH on adipose tissue in obese patients is not yet fully understood, In the study of Karakurt et al. (2009) the relationship between thyroid function and obesity was investigated and as a result, they stated that pituitary gland contributed to obesity independently of sT3 and sT4 by TSH.

The incidence of subclinical hypothyroidism increases with age. Especially, it is more common in women (Hollowell et al., 2002). In a study, while it is seen in $2.9 \%$ of men, it is seen in $11.6 \%$ of women. In addition, thyroid autoantibodies are positive in most patients because of the etiologic cause of Hashimato disease, which is the underlying cause of many patients with subclinical hypothyroidism (Parle et al., 1991). Because the diagnosis of subclinical hypothyroidism is clinically insignificant, it can often be difficult to diagnose. TSH measurement is helpful in the diagnosis of subclinical hypothyroidism with high sensitivity. With advanced age, the thyroid gland is atrophied. In these individuals, the level of sT4 decreases by $50-60 \%$, but with the decrease in sT4 consumption, the level of sT4 can be normal. Therefore, TSH level may be moderately high in patients. Patients are diagnosed with subclinical hypothyroidism with these laboratory values (Parle et al., 1991).

Both subclinical hypothyroidism and MetS are considered as atherogenic risk factors (Monzani et al., 2006). In both cases, it is important to increase the tendency for hypertension, dyslipidemia and hypercoagulation in patients (Foldes et al., 2004). The aim of this study was to evaluate the prevalence of Metabolic Syndrome, a risk factor for chronic diseases such as diabetes mellitus, cardiovascular diseases and stroke, in patients with subclinical hypothyroidism.

\section{Methods}

The records of 108 patients with subclinical hypothyroidism who were followed-up and treated at the Internal Medicine Department of Ordu University Faculty of Medicine between 2015-2018 were evaluated retrospectively. Free T4 (fT4) $(\mathrm{N}: 0.8-1.8 \mathrm{ng} / \mathrm{dL})$ and free $\mathrm{T} 3(\mathrm{fT} 3)(\mathrm{N}: 2.0-4.4$ $\mathrm{ng} / \mathrm{dL}$ ) levels in the normal range, TSH level between 4.2-10 ng/dL all patients older than 18 years of age with a diagnosis of subclinical hypothyroidism were included.

Age, gender, waist circumference, height, weight, blood pressure, HDL cholesterol and triglyceride levels and fasting blood glucose levels were recorded. Body mass index (BMI) was calculated. BMI was calculated by dividing the patient's weight (kilograms) by the square of height (meters). According to World Health Organization (WHO) criteria for the classification of BMI $<18.5$ $\mathrm{kg} / \mathrm{m}^{2}$, underweight; $18.5-24.9 \mathrm{~kg} / \mathrm{m}^{2}$, normal; 25 $29.9 \mathrm{~kg} / \mathrm{m}^{2}$, overweight; $30-39,9 \mathrm{~kg} / \mathrm{m}^{2}$, obese; $\geq 40$ $\mathrm{kg} / \mathrm{m}^{2}$ was determined as morbid obese. In addition, the obesity frequency was defined as obesity in accordance with the WHO criteria with a BMI $\geq 30$ $\mathrm{kg} / \mathrm{m}^{2}$. The waist circumference was measured from the plane passing between the lower costa and the spina iliaka anterior superior, while the patient was standing (World Health Organization (WHO), 1998). Blood pressure measurements were made using the sphygmomanometer from both arms in sitting position after resting for at least 15 minutes. After 8-12 hours fasting, HDL cholesterol and triglyceride values and fasting plasma glucose levels were evaluated. MetS diagnoses were made 
according to the National Cholesterol Education Program Adult Treatment Panel III (NCEP ATP III) guidelines (Table 1). Patients who had three and/or more positive criteria for the five criteria in the NCEP ATP III diagnostic guideline were accepted as MetS.

Table 1. National Cholesterol Education Program Adult Treatment Panel III Criteria for Metabolic Syndrome (NCEP ATP III).

\begin{tabular}{ll}
\hline \multicolumn{1}{c}{ Risk Factor } \\
\hline $\begin{array}{l}\text { Abdominal obesity } \\
\text { (Waist circumference) }\end{array}$ \\
\hline \multicolumn{3}{c}{ Male } & $>102 \mathrm{~cm}$ \\
\hline \multicolumn{3}{c}{ Female } & $>88 \mathrm{~cm}$ \\
\hline HDL Cholesterol & \\
\hline \multicolumn{3}{c}{ Male } & $<40 \mathrm{mg} / \mathrm{dL}$ \\
\hline Triglycerides & $>150 \mathrm{mg} / \mathrm{dL}$ \\
\hline Arterial blood pressure & $\geq 130 / 85 \mathrm{mmHg}$ \\
\hline Fasting plasma glucose & $\geq 100 \mathrm{mg} / \mathrm{dL}$ \\
\hline
\end{tabular}

Exclusion Criteria: Patients with incomplete and/or inadequate archive records, patients with thyroidectomy, patients with overt hypothyroidism, pregnant women, patients with chronic kidney disease and chronic liver disease, cardiovascular disease (such as hypertension, heart failure, coronary artery disease) and patients receiving treatment for diabetes mellitus, patients with malignancy, patients with cerebrovascular disease, patients with endocrine diseases that may cause obesity, and patients with MetS previously were excluded from the study.

Statistical Analysis: Statistical analyses were performed using IBM SPSS Statistics for Windows, Version 22.0. (IBM Corp. Armonk, NY). In the evaluation of the data; number (n), percentage (\%), mean and standard deviation were used for descriptive statistics. Data were analyzed by Kolmogorov-Smirnow test. Student-t test was used to compare the groups. Pearson and Spearman tests were used for correlation analysis. $\mathrm{P}$ value less than 0.05 was considered significant.

\section{Results}

The study included 108 patients with subclinical hypothyroidism. 74 patients were female $(68.5 \%)$ and $34(31.5 \%)$ were male. The mean age of the patients was $42.5 \pm 10.5$ years (mean age of female patients was $38.3 \pm 12.5$ years, and the mean age of male patients was $40.5 \pm 11.7$ years). The clinical and laboratory features of the patients with subclinical hypothyroidism were divided into two groups according to their gender and groups were compared in terms of BMI and MetS criteria (Table 2). Accordingly, there was a significant difference between male and female groups in height, weight, BMI, waist circumference, systolic blood pressure, diastolic blood pressure, triglyceride level and fasting plasma glucose levels $(\mathrm{p}=0.007 ; \mathrm{p}=0.032$; $\mathrm{p}=<0.001 ; \mathrm{p}=0.023 ; \mathrm{p}=<0.001 ; \mathrm{p}=0.021 ; \mathrm{p}=<0.001$; $\mathrm{p}=<0.001)$.

Table 2. Clinical and laboratory characteristics of patients diagnosed with subclinical hypothyroidism according to gender, comparison of values according to gender.

\begin{tabular}{|c|c|c|c|c|}
\hline Variables & $\begin{array}{l}\text { All patients } \\
\text { (n:108) }\end{array}$ & $\begin{array}{c}\text { Female } \\
\text { patients } \\
(\mathrm{n}: 74)\end{array}$ & $\begin{array}{l}\text { Male patients } \\
(\mathrm{n}: 34)\end{array}$ & $P$ value \\
\hline & Mean \pm SD & Mean \pm SD & Mean \pm SD & \\
\hline Age (years) & $42,5 \pm 10,5$ & $38,3 \pm 12,5$ & $39,5 \pm 11,7$ & 0,341 \\
\hline Height (cm) & $158 \pm 5,3$ & $162 \pm 4,2$ & $168 \pm 3,6$ & 0,007 \\
\hline Weight (kg) & $75,5 \pm 15,1$ & $80,7 \pm 14,7$ & $76,1 \pm 13,8$ & 0,032 \\
\hline BMI $\left(\mathrm{kg} / \mathrm{m}^{2}\right)$ & $31,5 \pm 6,7$ & $33,8 \pm 7,9$ & $29,6 \pm 8,5$ & $<0,001$ \\
\hline Obesity $($ BMI $>30$ kg/m²), $(\%)$ & 53,8 & 53,6 & 52,3 & 0,211 \\
\hline Waist circumference $(\mathrm{cm})$ & $98,6 \pm 16,9$ & $101,5 \pm 16,7$ & $93,2 \pm 13,2$ & 0,023 \\
\hline Systolic blood pressure (mmHg) & $121,3 \pm 18,2$ & $128,8 \pm 17,1$ & $114,2 \pm 17,4$ & $<0,001$ \\
\hline Diastolic blood pressure (mmHg) & $75,3 \pm 11,3$ & $78,8 \pm 14,7$ & $73,2 \pm 16,2$ & 0,021 \\
\hline HDL cholesterol level (mg/dL) & $49,7 \pm 14,2$ & $48,5 \pm 10,8$ & $48,4 \pm 12,7$ & 0,642 \\
\hline Triglyceride level (mg/dL) & $125,2 \pm 12,8$ & $158,6 \pm 16,8$ & $134,1 \pm 13,2$ & $<0,001$ \\
\hline Fasting plasma glucose (mg/dL) & $98,4 \pm 19,7$ & $104,2 \pm 14,6$ & $97,6 \pm 12,9$ & $<0,001$ \\
\hline MetS incidence (\%) & 42,6 & 47,3 & 30,8 & $<0,001$ \\
\hline
\end{tabular}

n: Number,\%: Percent, Mean \pm SD: Mean \pm standard deviation, BMI: Body mass index, HDL: High Density lipoprotein, MetS: Metabolic syndrome 
Table 3. Comparison of the frequency and gender of the metabolic syndrome components in male and female patients with subclinical hypothyroidism.

\begin{tabular}{lcccc}
\hline Variables & $\begin{array}{c}\text { All } \\
\text { patients } \\
(\mathbf{n : 1 0 8})\end{array}$ & $\begin{array}{c}\text { Female } \\
\text { patients } \\
(\mathbf{n : 7 4 )}\end{array}$ & $\begin{array}{c}\text { Male } \\
\text { patients } \\
(\mathbf{n : 3 4 )}\end{array}$ & P value \\
\hline Abdominal obezite, $(\%)$ & 52,8 & 54,6 & 51,3 & 0,021 \\
Low HDL cholesterol, (\%) & 54,6 & 57,3 & 52,2 & $<0,001$ \\
Increased Triglyceride, (\%) & 36,8 & 38,7 & 37,2 & 0,342 \\
Increased Fasting plasma glucose, (\%) & 18,7 & 24,7 & 6,8 & $<0,001$ \\
Increased Arterial blood pressure, (\%) & 39,1 & 43,6 & 23,7 & $<0,001$ \\
Metabolic Syndrome, (\%) & 42,6 & 47,3 & 30,8 & $<0,001$ \\
\hline
\end{tabular}

n: Number, \%: Percent, HDL: High Density lipoprotein.

The incidence of Metabolic Syndrome and Metabolic Syndrome components were evaluated for male and female patients with subclinical hypothyroidism. Accordingly, the incidence of MetS was $42.6 \%$ (47.3\% in females and $30.8 \%$ in males) in patients with subclinical hypothyroidism. MetS incidence was 1.5 times higher in female patients than in male patients. In addition, according to Metabolic Syndrome components, abdominal obesity, triglyceride elevation, fasting plasma glucose elevation and high blood pressure were higher in the female patient group ( $p=0.021$; p <0.001; p <0.001; p <0.001; 0.001) (Table 3). Among all patients, the most common MetS component was low HDL cholesterol (54.6\%) and abdominal obesity (52.8\%). This ranking was also valid for female and male groups (The frequency of HDL cholesterol in female group was $57.3 \%$, abdominal obesity frequency was $54.6 \%$, HDL cholesterol in male group was $52.2 \%$, abdominal obesity frequency was $51.3 \%$ ) (Table 3 ).

\section{Discussion}

Metabolic Syndrome, hyperglycemia, elevated blood pressure, dyslipidemia, visceral obesity, insulin resistance as well as hyperuricemia, microalbuminuria, atherothrombosis tendency and vascular inflammation with many features such as cardiovascular, metabolic and renal complications are among the most common and most important causes (Oguz, 2006). In general, a patient should be investigated for the underlying etiologic cause after the diagnosis of MetS. The most important reasons of MetS are sedentary life and obesity (Rennie et al., 2003). In addition, thyroid function should be evaluated in these patients. In a study, it was reported that the incidence of MetS increased in patients with normal free T4 levels and diagnosed as subclinical hypothyroidism (Roos et al., 2007). Also, in this study, it was stated that high TSH level caused insulin resistance in patients and played a role in the development of MetS. In our study, the incidence of MetS in patients with subclinical hypothyroidism was $42.6 \%$. In another study, it was found that subclinical hypothyroidism caused glucose intolerance in patients, increased tendency to hypertension, decreased HDL level and increased LDL level (Tamer et al., 2005). In our study, the majority of patients had low HDL levels (54.6\%), hypertension $(39.1 \%)$ and increased glucose (18.7\%).

Turkey Metabolic Syndrome Research Group (METSAR) published a report, the average incidence of the MetS in Turkey, 33.9\% (39.6\% for women and $28.0 \%$ among males) has announced (Kozan et al., 2007). According to the data of Turkish Adult Adults with Heart Disease and Risk Factors (TEKHARF), the prevalence of MetS in adults 30 years and older was $32.8 \%$ (38.6\% in women and 27\% in men) (Onat and Sansoy, 2002). Akbulut et al. (2011) found that the incidence of MetS was $30.2 \%$ in premenopausal women and $47.6 \%$ in postmenopausal women according to the NCEP ATP III criteria. Kitis et al. (2010) found the incidence of MetS to be $31.9 \%$. However, the incidence of MetS was higher in different literature studies. For example, Varlibas et al. (2006) found that the frequency of MetS was $67.2 \%$ in patients who were followed up due to ischemic cerebrovascular disease in the neurology department, while Baltali et al. (2004) found the prevalence of MetS as $44.8 \%$ after coronary bypass. In our study, we found the incidence of MetS in patients with subclinical hypothyroidism as $42.6 \%$ (47.3\% in women and $30.8 \%$ in men). However, in previous studies, we believe that MetS itself is an increased atherothrombotic and proinflammatory tendency because of the high 
prevalence of MetS. However, in our study, we believe that subclinical hypothyroidism has prepared itself for the development of MetS and that it is clinically associated with MetS. In a study carried out in Japan in 2006 and NCEP ATP III criteria were applied, the incidence of MetS was determined as $14.7 \%$ in women and $26.9 \%$ in men (Miyatake et al., 2006). According to the results of this study, the reason why our study rates are high may be due to the different nutritional habits of the countries, ethnicity, genetic factors and lifestyle characteristics.

Obesity, a component of metabolic syndrome, is an important risk factor for both cardiovascular diseases and many metabolic diseases. Demir et al. (2010) found that waist/hip ratio and BMI were higher in patients followed with MetS diagnosis and found that BMI was positively correlated with systolic blood pressure and diastolic blood pressure. In addition, in some studies, the risk of death in patients with BMI $>30 \mathrm{~kg} / \mathrm{m}^{2}$ was reported to be high (Onat et al., 2002; Bloomgarden, 2003). Also, in many studies, obesity has been reported to be included in changeable risk factors within MetS components (Bloomgarden, 2003; Misra and Khurana, 2009; Demir et al., 2010). In our study, the most common MetS component in patients with subclinical hypothyroidism was abdominal obesity (52.8\%). In a study by Tagliaferi et al. (2001), TSH levels of obese patients were significantly higher than the control group. They reported that TSH levels were normal in proportion to the weight they had given after their diet due to obesity. However, they reported that levothyroxine treatment for obese patients with high TSH levels did not alter the weight status and lipid profiles of the patients. In the light of all these findings, it is emphasized that elevated TSH level will be a cause of obesity etiology (Tagliaferi et al., 2001). Karakurt et al. (2009) in the study of the obese, TSH level was higher than the control group. However, no significant relationship was found between sT3-sT4 and obesity. As a result of this and similar studies, it is concluded that TSH is a risk factor independent of thyroid function in obesity (Bengel et al., 2003; Karakurt et al., 2009).

In addition, in some studies, subclinical hypothyroidism was not associated with MetS, but the rate of subclinical hypothyroidism was higher in the patients followed with the diagnosis of MetS than in the control group (Takashima et al., 2007). In a study by Shanta et al. (2009), they found the incidence of MetS in males with subclinical hypothyroidism in the Indian population, especially in female patients $(21.9 \%$ versus $6.6 \%)$. In our study, the incidence of MetS in female patients with hypothyroidism was 1.5 times higher than in male patients (47.3\% in females and 30.8\% in males). Some literature studies recommend levothyroxine treatment for patients diagnosed with subclinical hypothyroidism and MetS components. Although Levothyroxine treatment has been shown to improve MetS components, this approach has not yet been accepted by the authorities (Fadeyev et al., 2006; Villar et al., 2007). However, there is a need for studies that require extensive follow-up of the patients with levodyroxine treatment, which shows whether there is an improvement in MetS parameters in the long term.

\section{Conclusion}

In conclusion, the incidence of MetS was higher in women with subclinical hypothyroidism than in men. In addition, close follow-up of patients with subclinical hypothyroidism in terms of Metabolic Syndrome, which is a risk factor for many chronic diseases such as cardiovascular diseases, diabetes mellitus and stroke, will benefit in reducing the mortality of patients.

Ethics Committee Approval: Ethics committee approval was received for this study from Clinical Research Ethics Committee of Ordu University Medical Faculty. (Date: 25.04.2019, Decision Number: 2019-57).

Peer-review: Externally peer-reviewed.

Author Contributions: Concept-H.D.; DesignH.D.; Supervision-H.D.; Funding-None MaterialsH.D.; Data Collection/Data Process-H.D.; Analyze or Comment-H.D.; Literature Scanning-H.D.; Writer of Paper-H.D.; Critical Review-H.D.

Conflict of Interest: No conflict of interest was declared by the author.

Financial Disclosure: The author declared that this study hasn't received no financial support. 


\section{References}

Akbulut G. Does the Prevalence of metabolic syndrome in pre- and post-menopausal women differ by the ATP III and IDF Criteria? Turkiye Klinikleri J Med Sci 2011;31(6):1463-70.

Balkau B, Valensi P, Eschwe`ge E, Slamad G. A review of the metabolic syndrome. Diabetes Metab 2007;33:405-13.

Baltali M, Kizıltan HT, Korkmaz ME, Topcu S, Demirtas M, Topcuoglu S, et al. Ko Metabolic syndrome in patients after coronary bypass surgery: Prevalence and compliance with treatment. Anatol J Cardiol 2004;4:10-16.

Bengel FM, Lehnert J, Ibrahim T, Klein C, Bulow HP, Nekolla SG, et al. Cardiac oxidative metabolism, funtion and metabolic performance hypertiroidism: a noninvasive study using positron emission ton and magnetic resonance imaging, Thyroid 2003; 13: 471-7.

Bloomgarden ZT. American Association of Clinical Endocrinologists (AACE) consensus conference on the insulin resistance syndrome:25-26 August 2002, Washington, DC. Diabetes Care 2003;26:1297-03.

Demir D, Bucaktepe EG, Kara IH. The Comparing of the sociodemographic features, anthropometric and biochemical parameters of the cases with Metabolic Syndrome, Type 2 Diabetes Mellitus and healthy controls. Konuralp Medical Journal 2010;2(1):12-9.

Fadeyev VV, Sytch J, Kalashnikov V, Rojtman A, Syrkin A, Melnichenko G. Levothyroxine replacement therapy in patients with subclinical hypothyroidism and coronary artery disease. Endocr Pract 2006; 12: 5-17.

Foldes J, Banos C, Winkler G. Subclinical hypothyroidism and arteriosclerosis. Orv Hetil 2004; 145: 1601-7.

Ford ES, Giles WH, Dietz WH. Prevalence of the metabolic syndrome among US adults: findings from the Third National Health and Nutrition Examination Survey. JAMA 2002;287:356-9.

Grundy SM. Metabolic syndrome: connecting and reconcoling cardiovasculer and diabetes world. J Am Coll Cardiol 2006; 47: 1093-100.

Gupta A, Gupta R, Sarna M, Rastogi S, Grupta VP, Kothari K. Prevalence of diabetes, impaired fasting glucose and insulin resistance syndrome in an urban Indian population. Diabetes Res Clin Pract 2003;61:69-76.
Hollowell JG, Staehling NW, Flanders WD, Hannon WH, Gunter EW, Spencer CA, et al. 2002 Serum TSH, T4, and thyroid antibodies in the United States population (1988 to 1994): National Health and Nutrition Examination Survey (NHANES III). J Clin Endocrinol Metab 2002; 87: 489-99.

Karakurt F, Carkoglu A, Koroglu M, Us B, Kasapoglu B. Is thyroid function a risk factor for obesity? Yeni Tıp Dergisi 2009; 26:27-30.

Kitis Y, Bilgili N, Hisar F, Ayaz S. Frequency and affecting factors of metabolic syndrome in women older than 20 years of age. Anadolu Kardiyol Derg 2010;10:111-9.

Kllein I. Thyroid hormone and high blood pressure. In; Laragh JH, Brenner BM. Kaplan NM, editors. Endocrine mechasnism in hyper tension, 2nd ed. New York: Raven Pres; 1989. p.61-80.

Kozan O, Oguz A, Abaci A, Erol C, Ongen Z, Temizhan A, et al. Prevalence of the metabolic syndrome among Turkish adults (METSAR). Eur J Clin Nutr 2007; 61:548-53.

Lonn L, Stenlof K, Ottoson M, Lindoors AK, Mystrom E, Sjosstrom L. Body weight and body composition changes after treatment of hypothyroidism, Journal of Clinical Endocrinology and Metabolism 1998; 83: 426973.

Misra A, Khurana L. The metabolic syndrome in South Asians: epidemiology, determinants, and prevention. Metab Syndr Relat Disord 2009;7(6):497-14.

Miyatake N, Kawasaki Y, Nishikawa H, Takenami S, Numata T. Prevalence of metabolic syndrome in Okayama prefecture, Japan. Intern Med. 2006;45(2):107-8.

Monzani F, Dardano A, Caraccio N. Does treating subclinical hypothyroidism improve markers of cardiovascular risk? Treat Endocrinol 2006; 5: 65-81.

Morkin E, Flink IL, Goldman S. Biochemical and physiologic effects of thyroid hormone on cardiac performance. Prog Cardiovace Dis 1983; 25: 435-64. 
National Cholesterol Education Program (NCEP) Expert Panel on Detection. Evaluation, and Treatment of High Blood Cholesterol in Adults (Adult Treatment Panel III) Third Report of the National Cholesterol Education Program (NCEP) Expert Panel on Detection, Evaluation, and Treatment of High Blood Cholesterol in Adults (Adult Treatment Panel III) final report. Circulation 2002;106:3121-43.

Oguz A, Metabolic Syndrome, Ed. Ozata M, Yonem A, Endocrinology Metabolism and Diabetes. 1. bask1. Istanbul: Istanbul Medical pub; 2006:550-65.

Onat A, Ceyhan K, Basar O, Erer B, Toprak S, Sansoy V. Metabolic syndrome: major impact on coronary risk in a population with low cholesterol levels: prospective and crosssectional evaluation. Atherosclerosis 2002;165:285-92.

Onat A, Sansoy V. Metabolic Syndrome, Major Culprit of Coronary Disease Among Turks: Its Prevalence and Impact on Coronary Risk. Turk Kardiyol Dern Ars. 2002; 30(1): 8-15

Parle JV, Franklyn JA, Cross KW, Jones SC, Sheppard MC. Prevalence and follow-up of abnormal thyrotrophin (TSH) concentrations in the elderly in the United Kingdom. Clin Endocrinol (Oxf) 1991; 34: 77-83.

Reaven GM. Banting Lecture 1988. Role of insulin resistance in human disease. Diabetes. 1988; 37: 1595-607.

Rennie KL, McCarthy N, Yazdgerdi S, Marnot M, Brunner E. Association of the metabolic syndrome with both vigorous and moderate physical activity. Int J Epidemiol 2003; 32: 6006.
Roos A, Bakker SJ, Links TP, Gans RO, Wolffenbuttel BH. Thyroid function is associated with components of the metabolic syndrome in euthyroid subjects. $\mathrm{J}$ Clin Endocrinol Metab 2007; 92: 491-6.

Shantha GP, Kumar AA, Jeyachandran V, Rajamanickam D, Rajkumar K, Salim S, et al. Association between primary hypothyroidism and metabolic syndrome and the role of $\mathrm{C}$ reactive protein: a cross-sectional study from South India. Thyroid Res 2009; 2: 2.

Tagliaferi M, Berselli ME, Calo G, Minocci A, Savia G. Petroni ML, et al. Subclinical hypotroidism in obese patients: relation to resting energy expanditute serum leptin body compasition and lipid profile. Obes Res 2001; 9: 196-201.

Takashima N, Mannami T, Tomoike H, Iwai N. Characterization of subclinical thyroid dysfunction from cardiovascular and metabolic viewpoints: the Suita study. Circ J 2007; 71: 191-5.

Tamer I, Sargin M, Sargin H, Seker M, Babalik E, Tekce M, et al. The evaluation of left ventricular hypertrophy in hypertensive patients with subclinical hyperthyroidism. Endocr J 2005; 52:421-5.

Varlıbas F, Gencer M, Orken C, Cakal N, Tireli H. Metabolic syndrome in cerebrovascular diseases. Journal of Neurological Science 2006;23 (2):93-101.

Villar HC, Saconato H, Valante O, Atallah AN. Thyroid hormone replacement for subclinical hypothyroidism. Cochrane Database Syst Rev 2007: CD 003419.

World Health Organization. Prevention and management of the global epidemic of obesity. Report of the WHO Consultation on Obesity. Geneva: WHO; 1998 (Technical Report Series, No. 894). 